\title{
EVALUATION OF EFFECTIVE AREA OF ERBIUM DOPED FIBERS
}

\author{
J. Porins, A. Supe, and V. Bobrovs \\ Institute of Telecommunications, Riga Technical University, Azenes 12, LV-1048 Riga, Latvia \\ E-mail: jurgis.porins@rtu.lv
}

Received 31 August 2011; revised 5 February 2012; accepted 12 March 2012

\begin{abstract}
The effective area of an $\mathrm{Er}^{3+}$ doped fiber of 3\% erbium concentration was studied experimentally by the transverse shift measurement method for the excitation of 980 and $1480 \mathrm{~nm}$ wavelengths and at the amplification range of 1520-630 nm. Based on experimental results, the fiber effective area was calculated. A comparative analysis and estimation of the results for different wavelengths of an $\mathrm{Er}^{3+}$ doped fiber are given.
\end{abstract}

Keywords: erbium doped optical fibers, effective area, nonlinear optical effects, WDM

PACS: $42.65 . \mathrm{Hw}, 42.81 .-\mathrm{i}, 42.65 .-\mathrm{k}$

\section{Introduction}

The wave division multiplexing (WDM) technology makes it possible to transmit many data flows by one optical fiber. Among WDM-related amplification methods, the preference is given to the forced emission amplifiers of one class, i. e. the erbium doped optical fiber amplifiers (EDFAs). The wavelengths of optical signals amplified by C-band EDFAs are in the range from 1525 to $1565 \mathrm{~nm}$. The amplifiers of the type are distinguished by a comparatively lower noise; they are little sensitive to signal polarisation, have minor connection losses, and do not introduce inter-channel distortions. The EDFA design is based on fibers with a small controlled amount of erbium (a rare earth element) added to $\mathrm{SiO}_{2}$ in the form of $\mathrm{Er}^{3+}$ ion [1]. The light in the approximate range from 1530 to $1625 \mathrm{~nm}$ excites stimulated emission, thus achieving signal amplification, while the light of differing wavelengths passes through the amplifier invariable (Fig. 1). Almost entire inversion of Er ions could be achieved using a $980 \mathrm{~nm}$ excitation. Due to stimulated emission the inversion level of the exciting wavelength is usually lower if $1480 \mathrm{~nm}$ light is used. The quantum efficiency of the amplifier is higher at the use of $1480 \mathrm{~nm}$ pumping, since in this case a higher coincidence between signal and pump energies is reached [2].

An erbium doped fiber (EDF) has an interesting absorption spectrum shown in Fig. 1. There are three absorption maximums in the wavelength range used in telecommunications optical fibers. The most important for EDFAs are absorptions around 980 and $1530 \mathrm{~nm}$. They are related with erbium energy levels in a silica fiber. EDFAs use the

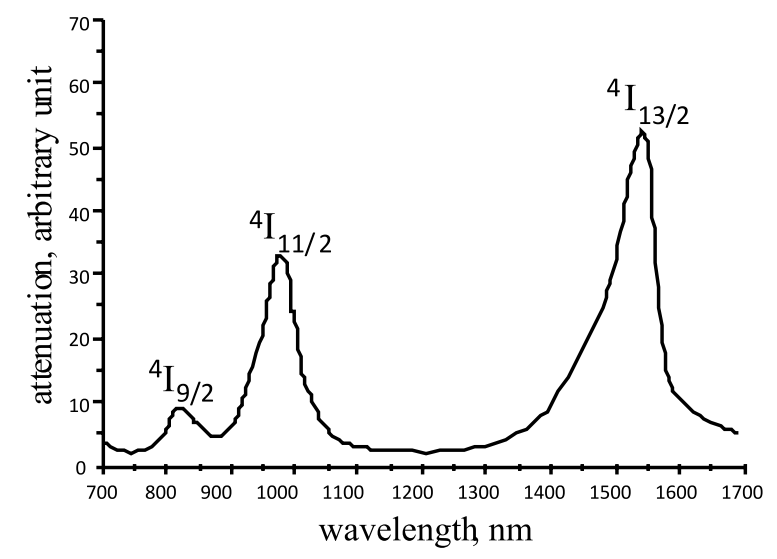

Fig. 1. Absorption spectrum of an erbium doped silica fiber [3]. 
energy level transition ${ }^{4} \mathrm{I}_{13 / 2} \rightarrow{ }^{4} \mathrm{I}_{15 / 2}$ to amplify wave- of the effective area is introduced in order to make lengths around $1550 \mathrm{~nm}$.

possible the calculations of nonlinear effects. This

The limitation of the optical field in the fiber parameter is based on the modal field distribution core takes place at reaching refractivity which and can be used in Eq. (1) instead of $A$ for calculaspecifies the basic mode of field distribution. An tion of the optical intensity value. The effective area important parameter characterising optical power can be defined as

and transmission is the effective area $A_{\text {eff }}$ which is determined by the power distribution. A standard single-mode fiber possesses a stepwise profile, and the power distribution in this case can be described by the Gaussian distribution where a greater power is obtained in the fiber centre and it is decreasing with increasing distance from it $[4,5]$. The effective area value is of importance in defining the nonlin- where $E_{\mathrm{a}}(r)$ is the amplitude, and $I(r)$ is the intenear effects in a fiber; therefore, it is useful to obtain sity of the near-field of the fundamental mode at a this value for a particular optical fiber with definite distance of radius $r$ from the central longitudina optical transmission parameters [6, 7].

axis of the fiber [3]

The aim of this research is to measure the effec- There are several methods how to measure the tive area of an $\mathrm{Er}^{3+}$ doped fiber at different wave- optical fiber effective area: near- and far-field oplength and power levels. The erbium doping level of tical radiation scanning as well as close distance this fiber is approximately $4 \%$. The cladding diame- imaging using CCD cameras. In this investigater is $125 \pm 1 \mu \mathrm{m}$, coating diameter is $245 \pm 10 \mu \mathrm{m}$, tion, the effective area was determined through and the cut-off wavelength is $1014 \mathrm{~nm}$. The manu- the transversal shift measurements, i. e. a far-field facturer of the fiber did not specify its effective area. distribution measurement method. This method Therefore, it was a challenging task to determine is based on a two fiber end transversal shift using the optical signal intensity in this type of the fiber a micro-positioner to perform the key operations: to continue research work for optimal EDFA para- positioning of the optical fiber and shifting it in the meters.

\section{Experiments and results}

All nonlinear effects depend on the electro-magnetic field intensity in the relevant environment. However, usually the total optical power at the fiber input and output is measured. The optical power measured at the fiber output is merely an integral from the intensity distribution over the entire area of the fiber cross-section. With this distribution being uniform, the intensity in a core with the area $A_{c}$ can be calculated from the measured power $P_{\mathrm{m}}$

$$
I=\frac{P_{\mathrm{m}}}{A_{\mathrm{c}}}
$$

(1)

However, a single-mode fiber field is not distributed uniformly, besides it does not fill completely the whole fiber volume. This field is stronger along the central longitudinal axis of the fiber and de- where $u=|u|$ is the shift from the fiber's central creases in the direction to the core-cladding inter- axis. The integrals are taken over the entire area $(S)$ face, forcing into the cladding depending on the where both fiber modes are overlapping. Integral real profile of fiber refractivity. So the parameter (3) can be written in polar coordinates, which gives:

\section{$C(u)=\int_{0}^{2 \pi \infty} \int_{0}^{\infty} E_{\mathrm{a}}(r) E_{\mathrm{a}}\left(r^{\prime}\right) r \mathrm{~d} r \mathrm{~d} \theta=\left[E_{\mathrm{a}}(r) * E_{\mathrm{a}}(r)\right]_{r=u},(4)$}

where $r^{2}=u^{2}+r^{2}-2 r u \cos (\varphi)$ and ${ }^{*}$ sign denotes a two-dimensional convolution. The Hänkel transformation convolution is described by the expression

$$
H\{\mathrm{C}(u)\}=H\left\{E_{\mathrm{a}}(r) * E_{\mathrm{a}}(r)\right\}=F^{2}(p),
$$

where $F^{2}(p)$ is the far-field power distribution in the fiber. Using equations (3) and (4) the power $C^{2}(u)$ transferred from one fiber to the other can be obtained for the central mode of the near-field power distribution by calculating it through the far-field power distribution. Further effective area can be obtained using the near-field power distribution.

In the measurements it is necessary that fiber ends are fully identical, since they should be placed the fibers on parallel planes was done by fixing them by fasteners arranged in parallel, each fiber being fixed by its opposite parallel fastener. One of the fasteners is immovable, securing the fiber with an optical radiation source at its second end. The second (receiving) fiber is placed on a movable platform, whose position can be varied by three stepping motors. Therefore, the receiving fiber could be centred against the source fiber thus achieving the maximum power of the transmitted optical signal. Actually, the connection of two ends of a fiber being formed, by varying the position of one of the fibers we could receive the maximum transmitted power. As a result of measurements, the far-field power distribution in fiber cross-sec tion was obtained. Then it was necessary to derive from this distribution the near-field power distribution and, finally, to calculate the value of the effective area of the fiber. In the measurement set-up (Fig. 2) there are also tunable laser sources in the range of $1520-1630 \mathrm{~nm}$ and $1465-1575 \mathrm{~nm}$ and a $980 \mathrm{~nm}$ laser diode. Lasers provide optical radiation with the optical signal power up to $+13 \mathrm{dBm}$ $(20 \mathrm{~mW})$. For optical power measurement at the output of the created optical connection the power and wavelength metre is used.

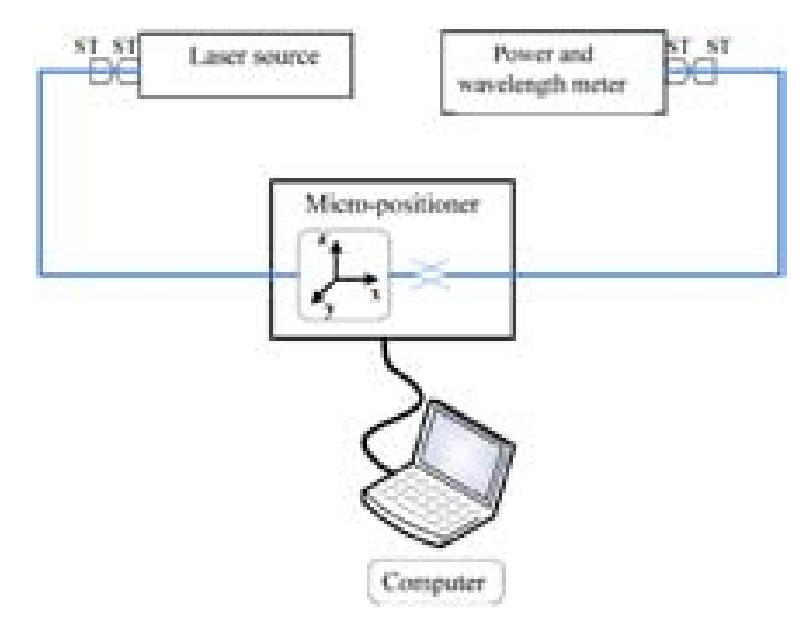

Fig. 2. The block diagram of the measurement breadboard.

In our experiment the measurements were taken at various parameters of the source's optical signal, with the power and wavelength of the optically issued signal varied. The purpose of such variations was to study the dependence of the effective area of an Er doped fibre on the two mentioned parameters. The results of measurements for one of wavelengths are shown in Fig. 3.

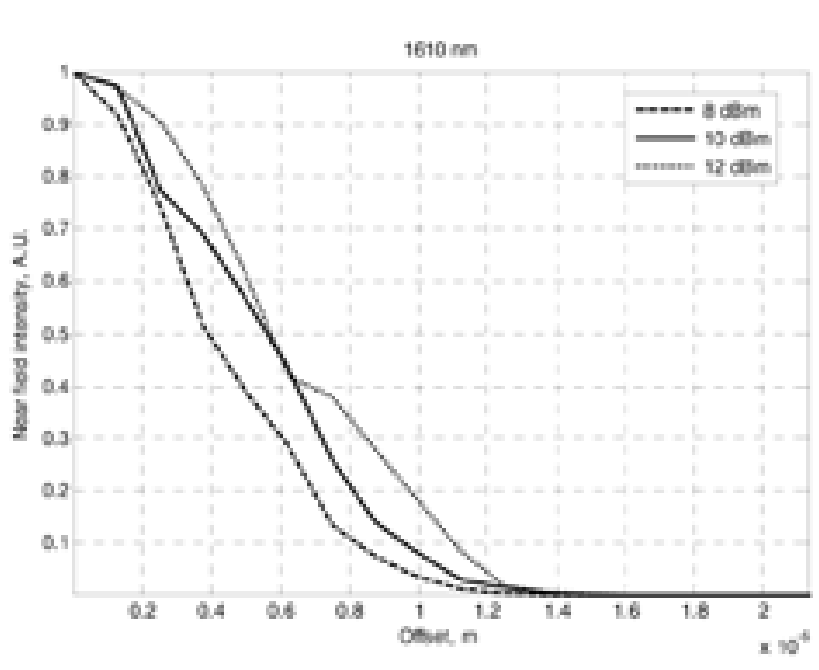

Fig. 3. The measured power distribution vs. fiber transverse shifting at $1610 \mathrm{~nm}$ and three input optical radiation power levels $(8,10$ and $12 \mathrm{dBm})$.

\section{Discussion}

Based on the measured power distribution results and the model for their processing described above the fiber effective area values are calculated. In total, 
21 different effective area values are calculated for seven different optical wavelength and three different input optical power levels. Table 1 presents EDF effective area results calculated using our written script in MatLab software.

Table 1. The measured $\mathrm{Er}^{3+}$ doped fiber effective area for different wavelength and power values of the optical signal.

\begin{tabular}{c|c|c|c}
\multicolumn{4}{|c}{ signal. } \\
\hline & \multicolumn{3}{|c}{$A_{\text {eff }} \mu \mathrm{m}^{2}$} \\
\hline$\lambda, \mathrm{nm}$ & $P_{\text {in }}=8 \mathrm{dBm}$ & $P_{\text {in }} 10 \mathrm{dBm}$ & $P_{\text {in }}=12 \mathrm{dBm}$ \\
\hline 980 & 49.50 & 50.46 & 51.42 \\
\hline 1480 & 61.91 & 65.21 & 68.51 \\
\hline 1520 & 64.33 & 70.34 & 72.07 \\
\hline 1550 & 67.03 & 68.28 & 70.72 \\
\hline 1580 & 67.16 & 68.95 & 72.00 \\
\hline 1610 & 67.48 & 69.48 & 73.21 \\
\hline 1630 & 68.32 & 70.77 & 76.34 \\
\hline
\end{tabular}

The values of the fiber effective area are in the range from $49.50 \mu \mathrm{m}^{2}$ at $\lambda=980 \mathrm{~nm}$ and $P_{\text {in }}=8 \mathrm{dBm}$ to $76.34 \mu \mathrm{m}^{2}$ at $\lambda=1630 \mathrm{~nm}$ and $P_{\mathrm{in}}=12 \mathrm{dBm}$. It is clearly seen that for $980 \mathrm{~nm}$ the measured effective area is considerably smaller than for other wavelengths. The explanation for this is that one of absorption maximums is at $\lambda=980 \mathrm{~nm}$. This wavelength is widely used as a pump in EDFAs because of erbium ion effective excitation to ${ }^{4} \mathrm{I}_{11 / 2}$ level (Fig. 1).

The results of the effective area for other wavelengths show closer dispersion so they were plotted in one graph (Fig. 4) for better understanding.

The standard ITU-T G.652 single mode fiber effective area is evenly increasing at a larger wavelength. For EDF, results are similar as we can see from Fig. 4. It shows the dependence of the measured effective area on the optical signal wavelength at three different power levels, 8,10 , and $12 \mathrm{dBm}$. This dependence, in contradistinction to the standard single mode fiber, is not even. We can see the local maximum around $1520 \mathrm{~nm}$ wavelength. To explain this we should look at the EDF absorption spectrum around 1420-1620 nm wavelength.

There is a marked absorption maximum around $\lambda=1530 \mathrm{~nm}$. But at the same time this wavelength overlaps with the EDF gain maximum when optically pumped at a definite wavelength (980 or

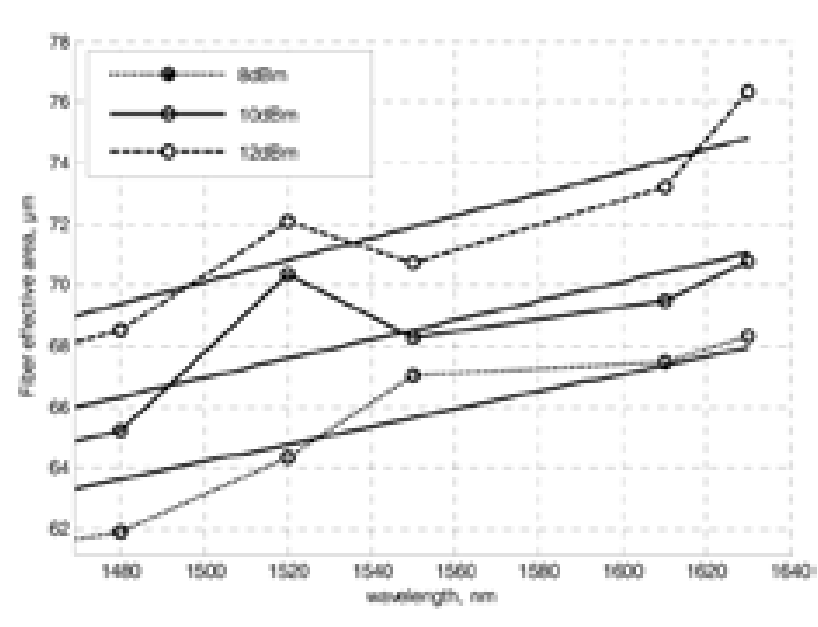

Fig. 4. Er doped fiber effective area vs. wavelength (nm) at three different optical power levels.

$1480 \mathrm{~nm})$. So we can conclude that effective area measurements interpret EDF characteristics as well as absorption spectral measurements due to similar wavelength dependence. To understand better, $A$ change measurements should be performed with smaller wavelength step to achieve more detailed information.

$A_{\text {eff }}$ measurements can give useful data about the fiber and optical signal propagation characteristics in it. These data would be useful for furthe improvement of EDFA amplification characteristics, for example a more even gain at the whole spectral range of amplification. EDF with more complicated profiles could be used to achieve necessary optical signal intensity at a different wavelength.

\section{Conclusions}

Although the EDFA amplification depends on the length of a doped fiber, it can be seen that its effective area changes determine the nonlinear optical effects generation, since at the input a large optical power is concentrated. The input power of the optical signal to be amplified plays a very importan role in long communication lines where a great number of EDFAs are appl fication changes depend on the signal wavelength The changes originate from the erbium emission and absorption profiles (Fig. 5). There are C-band, L-band, and wide-band EDF amplifiers. The EDFA amplification is maximal at $1530 \mathrm{~nm}$, nonlinearly

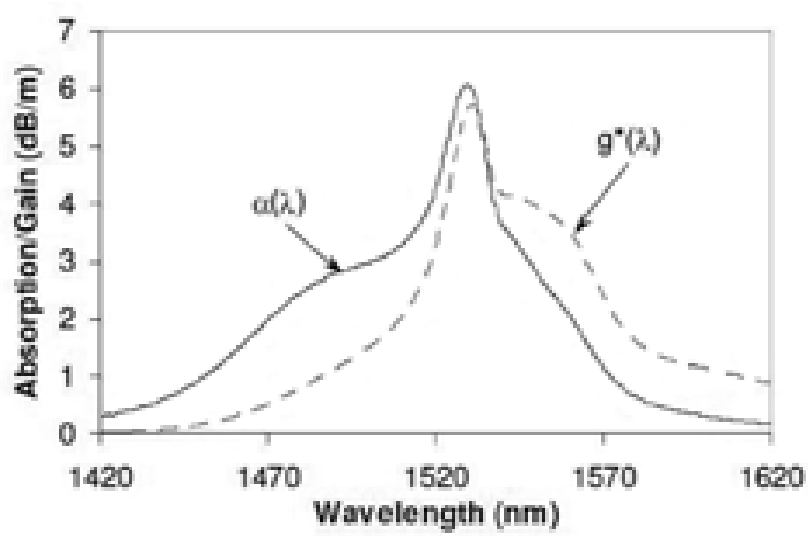

Fig. 5. Absorption $(\alpha)$ and gain $\left(g^{*}\right)$ parameters for an $\mathrm{E}$ doped fiber [9]

decreasing from this wavelength. Due to nonlindecreasing from this wavelength. Due to nonlin-
ear changes in the amplification coefficient, nonear changes in the amplification coefficient, non-
uniform amplification in the WDM system channels occurs. The difference in the channel levels can reach $2 \mathrm{~dB}$ if these channels are in the proximity of $1555 \mathrm{~nm}$ zone, and $10 \mathrm{~dB}$ if these channels are in the entire 1530-1565 nm C-band in the case of one amplifier. This research gives us a good EDF $A_{\text {eff }}$ evaluation. It is clear that EDF absorption and amplification characteristics affect fiber effective area which is actually the cause of these effects due to the optical signal intensity change. Our further research includes EDF $A_{\text {eff }}$ measurements around $\lambda=1530 \mathrm{~nm}$ and EDF nonlinear coefficient determination using picosecond optical pulses.

\section{Acknowledgments}

This work has been supported by the European Regional Development Fund within the project No. 2010/0270/2DP/2 1.1.1.0/10/APIA/VIAA/002

\section{References}

1] B. Mukherjee, Optical WDM Networks (Springer New York, 2006).

[2] S.A. Rodica, in: Advances in Optical Amplifiers, ed. P. Urquhart (InTech, Rijeka, 2011) pp. 255-280.

[3] A. Bjarklev, Optical Fiber Amplifiers: Design and System Application (Artech House, London, 1993) G.P. Agrawal, Nonlinear Fiber Optics, 3nd ed. (Academic Press, San Diego, 2001).

[5] R. Billington, Effective Area of Optical Fibres - Definition and Measurement Techniques (NPL, ECOC, 2000).

[6] T.J. Drapela, Effective area and nonlinear coefficient measurements of single-mode fibers: recent interlaboratory comparisons, National Institute of Standards and Technology, p. 5 (2000)

[7] J. Porins, G. Ivanovs, and A. Supe, Measurement of nonlinear coefficient in OS2 optical fibe A Supe and I. Porins 5 (101), $53-56$ (2010).

tical fiber non-linearity using self-phamation of opcfect

[9] C F. Alerin All fbre Devices for WDM Opt

C.I.G. Alegra, All-fibre Devices for WDM Optica Southampton, Faculty. Department of Electronics and Computer Science, 2001).

\section{ŠVIESOLAIDŽIU SU ERBIO PRIEMAIŠOMIS EFEKTYVIOJO PLOTO} IVERTINIMAS

J. Poriņ̌š, A. Supe, V. Bobrovs

Rygos technikos universiteto Telekomunikaciju institutas, Ryga, Latvija

Santrauk

Eksperimentiškai tirtas optiniu šviesolaidžių su er- $\quad$ iki $1630 \mathrm{~nm}$. Remiantis eksperimentụ rezultatais, subio priemaišomis efektyvusis plotas naudojant skersiilgių sužadinimui ir esant stiprinimo ruožui nuo 1520 kaičiuotas šviesolaidžio efektyvusis plotas. Straipsnyje giems bangų ilgiams šviesolaidyje su $\mathrm{Er}^{3+}$ priemaišomis. 